\title{
The Impact of Inter-platform Competition on the Economic Viability of Municipal Fiber Networks
}

\author{
Mathieu Tahon, Marlies Van der Wee, Sofie Verbrugge, Didier Colle, Mario Pickavet \\ IBCN-INTEC, Ghent University - iMinds, Gaston Crommenlaan 8b201, 9050 Ghent, Belgium \\ Mathieu.tahon@intec.ugent.be
}

\begin{abstract}
Local authorities investing in fiber broadband networks must meet the market investor principle. We apply a game theoretic approach to model the impact of inter-platform competition on the viability of the fiber business case.

OCIS codes: (060.0060) Fiber optics and optical communications; (060.4250) Networks
\end{abstract}

\section{Introduction}

The rollout of fiber networks in existing broadband market is expected to have a large impact on the competitive equilibrium. In case the newly deployed fiber network is rolled out by a third party, it will compete for retail customers with the legacy copper and cable infrastructures. When an incumbent rolls out the network, it will cannibalize revenues of their existing network. As a result, the fiber business case is expected to be put under pressure, since lower uptake due to competition significantly reduces the economic viability.

In Europe, the actors deploying the infrastructure are mostly not private ones. In Sweden, most physical fiber infrastructures have been deployed by municipalities (e.g. Stockholm). In the Netherlands, the city of Amsterdam has a share of $30 \%$ in the fiber deployment company $[1,2]$. The main rationale is that a fiber network has a public policy case, as it is expected to attract companies, to close the digital divide and increase tax income [3].

However, the investment of public money is bound to European regulation. The investment is only allowed in white areas, where no broadband infrastructure is currently available, or planned by private players to be deployed within the next three years [4]. In all other zones, public money can only be invested according to the market economy investor principle. The public player invests money on the same conditions as a private player would. Municipal infrastructure providers (MIP) that wish to deploy next generation access networks should proof that a viable business case can be obtained for the deployment, taking into account competition. In techno-economic analysis, the concepts and tools from game theory are used to model competitive interaction.

In this paper, the competitive game on the retail market between the legacy operators and the newly deployed MIP infrastructure is studied. A model is developed and tested on an FTTH deployment case in the city of Ghent, Belgium. It is indicated that deploying a fiber infrastructure in an urban environment is viable, even under competition with other infrastructures.

\section{Inter-platform competition with municipal fiber}

In the existing competitive environment, the rollout of a municipal fiber network will have an impact on the current market division. The emergence of a new broadband infrastructure and the resulting inter-platform (or interinfrastructure) competition could impact the existing market shares. Starting from the current situation, the introduction of new offers will churn retail customers from the existing offers. We refer to [5] and [6] for an introduction to and application of the modeling of market shares.

The presence of an FTTH network offers a range of new strategic options to the existing players, which will in turn impact the profitability of the MIP. In this research, the competition between an MIP, an existing infrastructure owner (Telco) and alternative network providers (ANP) is studied. ANPs are defined as players using leasing offers to offer broadband services.

\subsection{Strategic choices for the different operators}

The Telco has various possible strategies to react to the presence of a fiber infrastructure. The first strategy is continuing to use the legacy copper network. As the copper Telco has a significant market share on the retail market, lock-in effects could assure that their market share only decreases slowly. However, in case the newly deployed fiber network is an open access network, nothing withholds the Telco to formulate a fiber broadband offer. In this case, it buys wholesale access from the MIP. As a third strategy, the Telco can choose to deploy its own fiber network. Here, it needs to be taken into account that when deploying its own fiber network, the operator can engage in a joint infrastructure rollout [7]. 
Existing ANPs depend on leasing offers. For the ANPs, the emergence of an open access fiber infrastructure offers them the opportunity to choose between the fiber platform and the copper platform to provide retail services.

Up to here, the municipal fiber network was assumed to be an open access network. The MIP can also decide to allow only one ANP on its network and remain a closed network. In this case, the copper incumbent and ANPs will not be able to buy wholesale access on this network.

\subsection{Business models for competitors}

- For a description of the MIP and fiber ANP models, we refer to [8]. These model consists of an equipment dimensioning for central offices and street cabinets driven by customer uptake. Additionally, the total required trenching, ducts and fiber length was calculated using GIS based models. A comparable model was built for the synergetic rollout [7], where cost savings in deployment were taken into account.

- The Telco model is based on two different submodels, a wholesale model and a retail model. In the wholesale model, the costs and revenues the Telco incurs from offering access to ANPs are calculated. For the retail model, the cost is based on the bitstream access prices, supplemented with a cost for service provisioning. Additionally, an extra cost to connect a new customer is included. The revenue model is based on the monthly subscription price per customer. In case the Telco decides to roll out its own fiber network, the used model is comparable to the MIP model.

- Comparable to the Telco model, the ANP copper access model is based on a simplified cost-benefit model, starting from the existing regulated access prices. Per customer, the ANP pays a monthly price to the Telco. Again, extra costs were taken into account for service provisioning and customer connection. The revenue model simply multiplies the number of customers with the yearly income.

\section{Game theoretic analysis of inter-platform competition}

To model the market shares of the different offers, a market model was developed based on [5]. The monthly retail prices for the different offers can be found in [9].

\subsection{Impact of competition on the business cases}

The graphical representation of the game can be found in Fig. 1. The payoffs represent the NPV for each player after 25 years in millions $€$ in the form (payoff Telco, payoff Public MIP, payoff ANPs). It is immediately clear that under the given circumstances, an FTTH rollout is unviable in case the MIP chooses for a closed network. Even with an open access network, it is required that all players move towards this network to result in sufficient uptake for the MIP to have a positive business case. When looking at the rollout of two fiber infrastructures, it is clear that this is uninteresting for both infrastructure owners.

When analyzing the game in more detail, two Nash equilibria (NE) are obtained. The first is [STAY - CLOSED - COPPER] (indicated in gray in Fig. 1). In case the municipality chooses for a closed network, the Telco can only choose between two strategies, namely deploying its own network, or compete through the legacy copper network. The latter strategy clearly dominates the fiber deployment option. In this case the ANPs can only choose to continue buying access from the Telco. However, this NE is clearly negative for the business case of the municipal fiber network.

\begin{tabular}{|c|c|c|c|c|c|c|c|c|c|}
\hline & \multicolumn{6}{|c|}{ Public MIP } & & \\
\hline & & & OSED & & & OPEN & & & \\
\hline \multirow{6}{*}{$\frac{8}{\varrho}$} & \multirow{2}{*}{ STAY } & 10.50 & -23.00 & 0.78 & 10.50 & -30.00 & 0.78 & COPPER & \\
\hline & & $-\infty$ & $-\infty$ & $-\infty$ & 9.23 & -11.00 & 1.72 & FIBER & \\
\hline & \multirow{2}{*}{ MIGRATE } & $-\infty$ & $-\infty$ & $-\infty$ & 10.20 & -11.00 & 0.68 & COPPER & 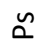 \\
\hline & & $-\infty$ & $-\infty$ & $-\infty$ & 9.28 & 0.57 & 1.46 & FIBER & $\ll$ \\
\hline & \multirow{2}{*}{ OWN } & -20.00 & -22.00 & 0.68 & -20.00 & -29.00 & 0.68 & COPPER & \\
\hline & & -4.20 & -35.00 & 1.46 & -26.00 & -12.00 & 1.46 & FIBER & \\
\hline
\end{tabular}

Fig. 1. Results from inter-platform competition under different strategies (in million $€$ )

The second NE is [MIGRATE - OPEN - FIBER] (indicated in negative in Fig. 1). In case of an open access network, the ANPs will migrate to the more profitable MIP network. In order to retain its market share in the broadband market, the Telco will also choose to migrate towards this MIP network. While this second competitive 
equilibrium could also result from the free competition between the different players, it is also the Pareto optimal strategic combination. In this point, no player can change its strategy to improve its payoff, without hurting another player. The MIP can influence the strategic choices of the competition. By choosing for an open access network, the physical network will attract the ANPs as well as the Telco, and have a viable business case.

\section{Conclusions}

Rolling out a fiber infrastructure as municipality will happen in the existing competitive broadband market. As a result, the new fiber based offers will have to compete for market share with existing legacy copper networks and cable networks. Additionally, when multiple ANPs are allowed on top of the physical infrastructure, intra-platform competition will most likely also impact the business case of the fiber infrastructure.

When investing, public authorities need to meet the market economy investor principle. In this paper, we indicated the importance of taking into account competitive interactions by modeling a realistic market environment. Secondly, by using a game theoretic analysis, we modeled the dynamic interaction between different operators and indicated the prevailing competitive equilibrium and the viability of the business case in each strategic combination.

In the specific case studied in this paper, two equilibria existed in this competitive environment. Either the fiber infrastructure was a closed infrastructure, forcing the existing operators to stay on the legacy networks. In this case the business case for the fiber network (MIP+ANP) was unviable. However, the second equilibrium, where the MIP opted for an open access infrastructure, resulted in existing players migrating to this infrastructure. As a result, the business case for the infrastructure provider improved significantly. This equilibrium is a NE, and could be reached under competitive interaction. However, the MIP can push the market towards the more preferred Nash equilibrium. In fact, the equilibrium where all players migrate towards the fiber network is also Pareto optimal, and is thus be preferred. The MIP can choose the playing field when deploying its infrastructure. By opening up the physical infrastructure, it can push the other actors towards the social optimal situation. In this situation, the payoff for the newly deployed fiber infrastructure is positive, while the other operators also have a positive business case. No player is inclined to move from this situation. In this case, a public player can obtain a positive business case, as required by regulation.

\section{Acknowledgment}

This research was carried out as part of the iMinds TERRAIN project. This project is co-funded by iMinds, IWT and Acreo AB, Alcatel-Lucent, Comsof, Deutsche Telekom Laboratories, Digipolis, FTTH Council Europe, Geosparc, Stad Gent, TMVW, TE Connectivity, UNET and WCS Benelux BV.

The work leading to these results has received funding from the European Union's Seventh Framework

Programme (FP7/2007-2013) under grant agreement $\mathrm{n}^{\circ} 249025$

The authors of this publication have received funding from the Agency for Innovation by Science and

Technology in Flanders (IWT)

\section{References}

[1] B. Felten, “Stockholm's Stokab: A Blueprint for Ubiquitous Fiber Connectivity," 2012.

[2] FTTH Council, "Amsterdam Citynet," 2010.

[3] M. Van der Wee, M. Driesse, B. Vandersteegen, P. Van Wijnsberge, S. Verbrugge, B. Sadowski, and M. Pickavet, "Identifying and quantifying the indirect benefits of broadband networks: a bottom-up approach," in Proceedings of the 19th ITS Biennal Conference, 2012, no. November.

[4] European Commission, "Community Guidelines for the application of State aid rules in relation to rapid deployment of broadband networks," COM (2009), no. 2005, pp. 7-25, 2009.

[5] M. Tahon, K. Casier, S. Verbrugge, D. Colle, M. Pickavet, and P. Demeester, "Market response modelling under competition: a modular approach", submitted to The Engineering Economist

[6] M. Tahon, B. Lannoo, J. Van Ooteghem, K. Casier, S. Verbrugge, D. Colle, M. Pickavet, and P. Demeester, "Municipal support of wireless access network rollout: A game theoretic approach," Telecommunications Policy, vol. 35, no. 9-10, pp. 883-894, Jun. 2011.

[7] M. Tahon, J. Van Ooteghem, K. Casier, S. Verbrugge, D. Colle, M. Pickavet, and P. Demeester, "Improving the FTTH business case - a joint telco-utility network rollout model," Telecommunications Policy, vol. in press, 2013.

[8] M. Van der Wee, K. Casier, K. Bauters, S. Verbrugge, D. Colle, and M. Pickavet, "A modular and hierarchically structured technoeconomic model for FTTH deployments," in Proceedings of ONDM 2012, 2012.

[9] TERRAIN, "D6.1. Multi Actor Analysis Results," 2012. 